\title{
An Overview of Talent Cultivation Models in Foreign Vocational Colleges
}

\author{
Youhua Wang \\ Hubei Urban Construction Vocational and Technological College \\ Wuhan 430205, China \\ E-mail: hubeiwyh@163.com
}

\begin{abstract}
A talent cultivation model refers to a model of the construction and operation of the cultivation process adopted by a school to achieve its cultivation objectives. Four models, with their differences and similarities, are introduced in this paper.
\end{abstract}

Keywords: Vocational colleges, Talent cultivation model

A talent cultivation model refers to a model of the construction and operation of the cultivation process adopted by a school to achieve its cultivation objectives.

Currently, four popular models of talent cultivation including "dual-script system", CBE model, TAFE model and MES model have their differences and similarities.

\section{Currently Popular Models of Vocational Talent Cultivation}

\section{1 "Dual-Script System"}

Represented by Germany, this model is characterized by the enterprise and the school taking joint commitment of talent cultivation. Accordingly, teaching and training activities are organized according to enterprises' requirements for their talents. Cultivated in this way, students will be familiar with the skills demanded at their future posts. Having gained popularity among enterprises, this model was once named "the secret weapon" in Germany's economic prosperity.

\subsection{CBE Model}

This model, represented by Canada and U.S., is based on capacity and sets its core at establishing capacity aims according to the actual demands of vocational posts. First, a curriculum development committee composed of enterprise experts is expected to lay down a capacity scale (a curriculum development form), capacities included in which are based on to establish courses, organize teaching contents and assessing capacities.

\subsection{TAFE Model}

This model, represented by Australia, is a comprehensive cultivation model involving multi independent levels under the national framework in which industry exerts its propelling forces, government, industry and schools are combined, teaching activities are conducted centering on students, the cultivation process is joined with middle school education and college education.

\subsection{MES Model}

MES (Modules of Employable Skills) lays down all functions required by a post or a job by establishing post descriptions, then divide them into different tasks and name each one of them as a module. According to the actual demands in each module, each part of knowledge and skills required in fulfilling a module's takes is a unit. Actually, based on system theory, information theory and control theory, MES is a typical vocational training model employing the three theories.

\section{Differences among the Talent Cultivation Models}

\subsection{Different Backgrounds}

"Dual-script system" came into being in the middle and late $19^{\text {th }}$ century. With the beginning of industrialization, traditional apprentice training exposed its shortcomings in improving apprentices' academic capacities and meeting new demands. Therefore, it was laid down that apprentices had to have necessary theoretical knowledge training at vocational schools. By 1900, apprentices' school training had been named compulsory education and enterprises had been expected to take major responsibilities in vocational training. In addition, vocational school education was combined with on-the-spot practice, hence forming "dual-script system".

CBE found its origin in system theory and behavioral sciences in 1950s and 1960s, according to which people's demands, motivation, belief, attitudes and expectations played critical role in their behavior. Seen from the perspective 
of economy, industry called for attention from the education departments to their actual demands for talents in 1970s and 1980s. Therefore, capacity-oriented education arose.

In 1980s, due to the deterioration of commerce and the decline of the former pillar industries, Australia's economy was greatly affected. During their efforts for economic revival and industrial reconstruction, the Australian Government realized the importance of reforming vocational education and its training system, expanding training subjects and improving training performance. In April, 1989, a special ministerial meeting on vocational training was held in Australia, at which an agreement on reforms was made to establish a national training department intended to instruct developing national capacity standards and to set up an educational system based on capacity.

MES Model was created by International Labor Organization in the end of 1970s and early 1980s by referring to Germany and Sweden's periodic training model as well as Britain, U.S. and Canada's modularized training and employing system theory, information theory and control theory in order to help all countries especially developing countries to improve the low efficiency in technological workers' training.

\subsection{Different Curriculum Models}

\subsubsection{Different Curriculum Development}

Based on the contents on professional education in vocational schools listed in the general teaching plan agreed on at the cultural and educational minister conference, "dual-script" curriculum is laid down by the ministers of culture and education in each state according to their reality.

When developing CBE course, first of all, the DACUM Committee composed of professional experts conducts a comprehensive capacity analysis, which is then followed by the analysis on specific capacities involved in each comprehensive item, hence forming a DACUM table. After that, a committee responsible for specific capacity analysis forms brief written descriptions on each specific capacity listed in the DACUM table and divide them into different categories such as learning steps, necessary knowledge and so on. Finally, a teaching analysis committee composed of education experts designs learning units and confirms core courses.

In TAFE Model, different educational service departments are established to deal with curriculum development according to different categories of occupations and courses based on the training aims set by the national occupational consultation institution. In conformity to the requirements of different posts, necessary knowledge and skills are divided and relevant professional standards are converted into courses.

In MES Model, the global occupational classification and tasks involved in all working fields are based on to form skill modules. Curriculum development staff is expected to create the learning unit bank and curriculum modules.

\subsubsection{Different Curriculum Settings}

There are two types of courses in "dual-script system": the theoretical course and the practical course. The former includes the learning of general knowledge and basic professional theory at vocational schools while the latter is mainly conducted in enterprises. Of course, the two parts are interwoven with each other since students have access to necessary theoretical knowledge in the practice classrooms provided by enterprises and vocational schools are also equipped with workshops for students' practice.

Differently, in CBE Model, students' individual differences instead of universal contents and pace are emphasized. With modules and credits combined together in this model, different students have the freedom to choose different learning models and set different curriculum plans for themselves according to their abilities and demands.

Different from "dual-script system", there is no public basic course in TAFE Model. Only basic and advanced courses related to certain major are provided. In spite of the large number of its professional courses, class hours are limited and there are optional courses as well as compulsory ones.

Seen from the above, "dual-script system" is still knowledge-oriented, which puts greater emphasis on the systematicness and completeness of academic knowledge and the organization of courses according to the logical order of different branches of study. Instead, the other three models have turned to be capacity-oriented, which develop learning modules according to capacity elements by employing modularized curriculum structure and centering on vocational capacity instead of pursuing academic logics.

\subsection{Different Cultivation Methods}

In "dual-script system", talents are mainly cultivated by enterprises. Students' time spent in the enterprise and school is $4: 1$ and vocational schools provide only part-time education.

In CBE Model, students achieve their cultivation goals mainly through their own efforts with the learning condition and assistance offered by their school and teachers.

Differently, TAFE seems more flexible because students have the freedom to choose to study at school, at the working 
place or even at home. As long as they have got enough credits, they can gain their certificates and diplomas.

In MES, another flexible cultivation model, anyone can choose his individual learning method despite of his age or working experience. With the emphasis on students, learning stations and skills, students can fulfill their training tasks by teaching themselves or learning at learning stations and have their achievements assessed through the final examination.

\section{Similarities among the Talent Cultivation Models}

\subsection{Emphasizing Practice}

Students' practice, skills and techniques are particularly emphasized during the training process in "dual-script system". The ratio of theory to practice is 3:7 or 2:8. In addition, applicability of theoretical education is also emphasized and the two sections are closely related to each other to meet the demands of practice.

Most CBE teaching activities are conducted in practice classrooms which appear to be practice workshops but actually are equipped with advanced facilities.

TAFE requires perfect on-campus practice bases. Classrooms are also labs, hence combining learning environment with working environment to cultivate students' practical abilities. In such classrooms filled with teaching tools and experiment facilities, students have access to practice as well as theoretical knowledge and extra-curricular practice. As a result, education efficiency and students' efficiency in grasping knowledge and skills are improved a lot.

MES has perfect learning stations, experienced trainers, advanced facilities and places, providing sufficient and advanced learning and practice conditions. The combination of classrooms and labs provides favorable learning environment and working environment as well. In addition, teachers who are picked out from professional technicians are all experienced in practice.

\subsection{Realizing Better Communication between Enterprises and Schools}

Enterprise and school are two fundamental elements in "dual-script system" with the former emphasizing practical skills while the latter putting greater importance on theoretical knowledge.

CBE begins with occupational analysis which is intended to learn about enterprises and institutions in the service area, vacancies in certain occupations, demands for the improvement of staff capacity in certain occupations and to develop courses fit for an individual school. Professional experts who know well about the capacity required by an occupation are responsible for curriculum development while the task of designing teaching contents has to be given to educational experts. This is in better conformity to educational rules and also achieves better communication between enterprises and schools.

There are two groups of experts in TAFE Model: entrepreneurs who are not only equipped with teaching experience and academic capacity but also familiar with economic development and enterprise history due to their direct participation in corporate management are responsible for conducting educational researches, offering suggestion and consultation, conducting specialty settings and curriculum design and so on; educational experts who are experienced in management and practice as well as education emphasize the importance of designing specialties and courses according to the actual demands of enterprises in order to realize better communication between enterprises and schools.

In MES Model, the confirmation of occupational fields, the design of skill modules, the composition of learning units and the development of training outlines should be based on surveys on occupations, types of work and the most advanced facilities and techniques in order to exactly reflect the actual demands of enterprises for skills and techniques.

\section{Lessons from the Foreign Models}

Foreign vocational talent cultivation models have been converted from the classical ones into a diversified pattern which conforms better to local economic and social development. Lying in the current stage of popularization of higher education, the development of higher vocational education is of great importance in China. We can learn some helpful lessons from those foreign models.

Higher vocational education reflects the demands for talent cultivation reform with the development of economic society. Seen from the experience of foreign higher vocational education, it is an important guarantee for vocational education's sound development to set up talent cultivation models in conformity to a country's economic development and reality.

The development of higher vocational education is a systematic project, therefore, the efforts of educational departments and higher vocational colleges are far from enough. The idea of "broad education" must be based on to fully exert the government's macro-control and administrative legislation, to stimulate enterprises' enthusiasm to participate in talent cultivation and to inspire the passion and confidence for vocational colleges to innovate their talent cultivation models. 
Despite their different cultivation methods, those foreign talent cultivation models have it in common to emphasize the analysis and cultivation of capacities, the construction of modularized courses and skill trainings based on occupational classification and capacity types as well as students' practice in real enterprise environment or virtual situations.

Certainly, the cultivation of different technological talents has their specialties as well as common rules. Therefore, it has been a necessary tendency in the reform and innovation of higher vocational talent cultivation models to increase practice opportunities, to realize the combination of on-campus and off-campus practice bases, to innovate teaching supervision system and to establish flexible cultivation schemes including necessary quality standards.

\section{References}

Lu, Xinxiang. (2001). A Study on the Character of Higher Vocational and Technical Education Curriculum. Shanghai Higher Education.

Wang, Qianxin. (2003). Higher Vocational Education. Shantou University Press.

Zhang, Jun. (2008). A Study on "Work-Study Combined" Model of Talent Cultivation at Vocational School. Journal of Northwest A\&F University.

Zheng, Guoqiang. (2005). An Overview of Vocational Talent Cultivation Models. Vocational \& Technical Education Forum. 